\title{
Smart Cities and the Future Internet: Towards Cooperation Frameworks for Open Innovation
}

\author{
Hans Schaffers ${ }^{1}$, Nicos Komninos ${ }^{2}$, Marc Pallot ${ }^{3}$, Brigitte Trousse ${ }^{3}$, \\ Michael Nilsson ${ }^{4}$, Alvaro Oliveira ${ }^{5}$ \\ ${ }^{1}$ ESoCE Net \\ hschaffers@esoce.net \\ ${ }^{2}$ Urenio, Aristotle University of Thessaloniki \\ komninos@urenio.org \\ ${ }^{3}$ INRIA Sophia Antipolis, \\ marc.pallot@inria.fr, brigitte.trousse@inria.fr \\ ${ }^{4}$ CDT Luleå University of Technology \\ michael.nilsson@cdt.1tu.se \\ ${ }^{5}$ Alfamicro Lda \\ alvaro.oliveira@alfamicro.pt
}

\begin{abstract}
Cities nowadays face complex challenges to meet objectives regarding socio-economic development and quality of life. The concept of "smart cities" is a response to these challenges. This paper explores "smart cities" as environments of open and user-driven innovation for experimenting and validating Future Internet-enabled services. Based on an analysis of the current landscape of smart city pilot programmes, Future Internet experimentally-driven research and projects in the domain of Living Labs, common resources regarding research and innovation can be identified that can be shared in open innovation environments. Effectively sharing these common resources for the purpose of establishing urban and regional innovation ecosystems requires sustainable partnerships and cooperation strategies among the main stakeholders.
\end{abstract}

Keywords: Smart Cities, Future Internet, Collaboration, Innovation Ecosystems, User Co-Creation, Living Labs, Resource Sharing

\section{Introduction}

The concept of "smart cities" has attracted considerable attention in the context of urban development policies. The Internet and broadband network technologies as enablers of e-services become more and more important for urban development while cities are increasingly assuming a critical role as drivers of innovation in areas such as health, inclusion, environment and business [1]. Therefore the issue arises of how cities, surrounding regions and rural areas can evolve towards sustainable open and user-driven innovation ecosystems to boost Future Internet research and experimentation for user-driven services and how they can accelerate the cycle of research, inno- 
vation and adoption in real-life environments. This paper pays particular attention to collaboration frameworks which integrate elements such as Future Internet testbeds and Living Lab environments that establish and foster such innovation ecosystems.

The point of departure is the definition which states that a city may be called 'smart' "when investments in human and social capital and traditional (transport) and modern (ICT) communication infrastructure fuel sustainable economic growth and a high quality of life, with a wise management of natural resources, through participatory government" [2]. This holistic definition nicely balances different economic and social demands as well as the needs implied in urban development, while also encompassing peripheral and less developed cities. It also emphasises the process of economic recovery for welfare and well-being purposes. Secondly, this characterisation implicitly builds upon the role of the Internet and Web 2.0 as potential enablers of urban welfare creation through social participation, for addressing hot societal challenges, such as energy efficiency, environment and health.

Whereas until now the role of cities and regions in ICT-based innovation mostly focused on deploying broadband infrastructure [3], the stimulation of ICT-based applications enhancing citizens' quality of life is now becoming a key priority. As a next step, the potential role of cities as innovation environments is gaining recognition [4]. The current European Commission programmes FP7-ICT and CIP ICT-PSP stimulate experimentation into the smart cities concept as piloting user-driven open innovation environments. The implicit aim of such initiatives is to mobilise cities and urban areas as well as rural and regional environments as agents for change, and as environments of "democratic innovation" [5]. Increasingly, cities and urban areas are considered not only as the object of innovation but also as innovation ecosystems empowering the collective intelligence and co-creation capabilities of user/citizen communities for designing innovative living and working scenarios.

Partnerships and clear cooperation strategies among main stakeholders are needed in order to share research and innovation resources such as experimental technology platforms, emerging ICT tools, methodologies and know-how, and user communities

Table 1. Three perspectives shaping the landscape of Future Internet and City Development

\begin{tabular}{|c|c|c|c|}
\hline & $\begin{array}{l}\text { Future Internet } \\
\text { Research }\end{array}$ & $\begin{array}{l}\text { Cities and Urban } \\
\text { Development }\end{array}$ & $\begin{array}{l}\text { User-Driven } \\
\text { Innovation Ecosystems }\end{array}$ \\
\hline Actors & $\begin{array}{l}\text { Researchers } \\
\text { ICT companies } \\
\text { National and EU actors }\end{array}$ & $\begin{array}{l}\text { City policy actors } \\
\text { Citizen platforms } \\
\text { Business associations }\end{array}$ & $\begin{array}{l}\text { Living Lab managers, } \\
\text { citizens, governments, } \\
\text { enterprises, researchers } \\
\text { as co-creators }\end{array}$ \\
\hline Priorities & $\begin{array}{l}\text { Future Internet technical } \\
\text { challenges (e.g. routing, } \\
\text { scaling, mobility) }\end{array}$ & $\begin{array}{l}\text { Urban development } \\
\text { Essential infrastructures } \\
\text { Business creation }\end{array}$ & $\begin{array}{l}\text { User-driven open } \\
\text { innovation } \\
\text { Engagement of citizens }\end{array}$ \\
\hline Resources & $\begin{array}{l}\text { Experimental facilities } \\
\text { Pilot environments } \\
\text { Technologies }\end{array}$ & $\begin{array}{l}\text { Urban policy framework } \\
\text { Organisational assets } \\
\text { Development plans }\end{array}$ & $\begin{array}{l}\text { Living lab facilities: } \\
\text { methodologies \& tools, } \\
\text { physical infrastructures }\end{array}$ \\
\hline Policies & $\begin{array}{l}\text { Creation of advanced and } \\
\text { testbed facilities } \\
\text { Federated cooperation } \\
\text { Experimental research }\end{array}$ & $\begin{array}{l}\text { City policies to stimulate } \\
\text { innovation, business and } \\
\text { urban development } \\
\text { Innovative procurement }\end{array}$ & $\begin{array}{l}\text { User-driven innovation } \\
\text { projects } \\
\text { Open, collaborative } \\
\text { innovation }\end{array}$ \\
\hline
\end{tabular}


for experimentation on Future Internet technologies and e-service applications. Common, shared research and innovation resources as well as cooperation models providing access to such resources will constitute the future backbone of urban innovation environments for exploiting the opportunities provided by Future Internet technologies. Three perspectives are addressed in this paper in order to explore the conditions for rising to this challenge (see Table 1).

The first perspective of Future Internet research and experimentation represents a technology-oriented and longer term contribution to urban innovation ecosystems. Cities and urban areas provide a potentially attractive testing and validating environment. However, a wide gap exists between the technology orientation of Future Internet research and the needs and ambitions of cities. Hence, the second perspective is comprised of city and urban development policies. City policy-makers, citizens and enterprises are primarily interested in concrete and short-term solutions, benefiting business creation, stimulation of SMEs and social participation. While many cities have initiated ICT innovation programmes to stimulate business and societal applications, scaling-up of pilot projects to large-scale, real-life deployment is nowadays crucial. Therefore, a third perspective is the concept of open and user-driven innovation ecosystems, which are close to the interests and needs of cities and their stakeholders, including citizens and businesses, and which may bridge the gap between short-term city development priorities and longer term technological research and experimentation.

A key challenge is the development of cooperation frameworks and synergy linkages between Future internet research, urban development policies and open userdriven innovation. Elements of such frameworks include sharing of and access to diverse sets of knowledge resources and experimentation facilities; using innovative procurement policies to align technology development and societal challenges; and establishing open innovation models to create sustainable cooperation. The concept of open and user-driven innovation looks well positioned to serve as a mediating, exploratory and participative playground combining Future Internet push and urban policy pull in demand-driven cycles of experimentation and innovation. Living Labdriven innovation ecosystems may evolve to constitute the core of "4P" (PublicPrivate-People-Partnership) ecosystems providing opportunities to citizens and businesses to co-create, explore, experiment and validate innovative scenarios based on technology platforms such as Future Internet experimental facilities involving SMEs and large companies as well as stakeholders from different disciplines.

This paper is structured as follows. Section 2 addresses challenges for cities to exploit the opportunities of the Future Internet and of Living Lab-innovation ecosystems. How methodologies of Future Internet experimentation and Living Labs could constitute the innovation ecosystems of smart cities is discussed in section 3. Initial examples of such ecosystems and related collaboration models are presented in section 4. Finally, section 5 presents conclusions and an outlook.

\section{City and Urban Development Challenges}

In the early 1990s the phrase "smart city" was coined to signify how urban development was turning towards technology, innovation and globalisation [6]. The World Foundation for Smart Communities advocated the use of information technology to 
meet the challenges of cities within a global knowledge economy [7]. However, the more recent interest in smart cities can be attributed to the strong concern for sustainability, and to the rise of new Internet technologies, such as mobile devices (e.g. smart phones), the semantic web, cloud computing, and the Internet of Things (IoT) promoting real world user interfaces.

The concept of smart cities seen from the perspective of technologies and components has some specific properties within the wider cyber, digital, smart, intelligent cities literatures. It focuses on the latest advancements in mobile and pervasive computing, wireless networks, middleware and agent technologies as they become embedded into the physical spaces of cities. The emphasis on smart embedded devices represents a distinctive characteristic of smart cities compared to intelligent cities, which create territorial innovation systems combining knowledge-intensive activities, institutions for cooperation and learning, and web-based applications of collective intelligence $[8,9]$.

\section{Box: A New Spatiality of Cities - Multiple Concepts}

Cyber cities, from cyberspace, cybernetics, governance and control spaces based on information feedback, city governance; but also meaning the negative / dark sides of cyberspace, cybercrime, tracking, identification, military control over cities.

Digital cities, from digital representation of cities, virtual cities, digital metaphor of cities, cities of avatars, second life cities, simulation ( $\operatorname{sim}$ ) city.

Intelligent cities, from the new intelligence of cities, collective intelligence of citizens, distributed intelligence, crowdsourcing, online collaboration, broadband for innovation, social capital of cities, collaborative learning and innovation, people-driven innovation.

Smart cities, from smart phones, mobile devices, sensors, embedded systems, smart environments, smart meters, and instrumentation sustaining the intelligence of cities.

It is anticipated that smart city solutions, with the help of instrumentation and interconnection of mobile devices, sensors and actuators allowing real-world urban data to be collected and analysed, will improve the ability to forecast and manage urban flows and push the collective intelligence of cities forward [10]. Smart and intelligent cities have this modernisation potential because they are not events in the cybersphere, but integrated social, physical, institutional, and digital spaces, in which digital components improve the functioning of socio-economic activities, and the management of physical infrastructures of cities, while also enhancing the problemsolving capacities of urban communities.

The most urgent challenge of smart city environments is to address the problems and development priorities of cities within a global and innovation-led world. A recent public consultation held by the European Commission [11] on the major urban and regional development challenges in the EU has identified three main priorities for the future cohesion policy after 2013. It appears that competitiveness will remain at the heart of cohesion policy, in particular, research, innovation, and upgrading of skills to promote the knowledge economy. Active labour market policy is a top priority to sustain employment, strengthen social cohesion and reduce the risk of poverty. Other hot societal issues are sustainable development, reducing greenhouse gases emissions and improving the energy efficiency of urban infrastructure. Smart city 
solutions are expected to deal with these challenges, sustain the innovation economy and wealth of cities, maintain employment and fight against poverty through employment generation, the optimisation of energy and water usage and savings, and by offering safer cities. However, to achieve these goals, city authorities have to undertake initiatives and strategies that create the physical-digital environment of smart cities, actualising useful applications and e-services, and assuring the long-term sustainability of smart cities through viable business models.

The first task that cities must address in becoming smart is to create a rich environment of broadband networks that support digital applications. This includes: (1) the development of broadband infrastructure combining cable, optical fibre, and wireless networks, offering high connectivity and bandwidth to citizens and organisations located in the city, (2) the enrichment of the physical space and infrastructures of cities with embedded systems, smart devices, sensors, and actuators, offering realtime data management, alerts, and information processing, and (3) the creation of applications enabling data collection and processing, web-based collaboration, and actualisation of the collective intelligence of citizens. The latest developments in cloud computing and the emerging Internet of Things, open data, semantic web, and future media technologies have much to offer. These technologies can assure economies of scale in infrastructure, standardisation of applications, and turn-key solutions for software as a service, which dramatically decrease the development costs while accelerating the learning curve for operating smart cities.

The second task consists of initiating large-scale participatory innovation processes for the creation of applications that will run and improve every sector of activity, city cluster, and infrastructure. All city economic activities and utilities can be seen as innovation ecosystems in which citizens and organisations participate in the development,

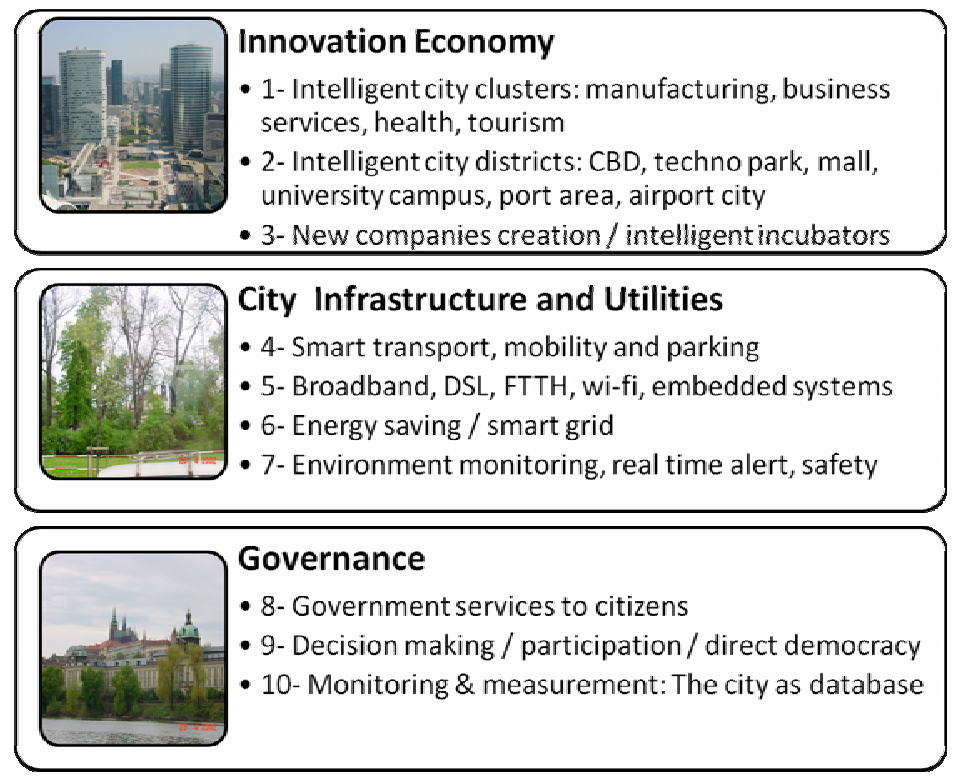

Fig. 1. Smart city key application areas 
supply and consumption of goods and services. Fig. 1 presents three key domains of potential smart city applications in the fields of innovation economy, infrastructure and utilities, and governance.

Future media research and technologies offer a series of solutions that might work in parallel with the Internet of Things and embedded systems, providing new opportunities for content management [12, 13]. Media Internet technologies are at the crossroads of digital multimedia content and Internet technologies, which encompasses media being delivered through Internet networking technologies, and media being generated, consumed, shared and experienced on the web. Technologies, such as content and context fusion, immersive multi-sensory environments, location-based content dependent on user location and context, augmented reality applications, open and federated platforms for content storage and distribution, provide the ground for new e-services within the innovation ecosystems of cities (see Table 2).

Table 2. Media Internet technologies and components for Smart Cities

\begin{tabular}{|c|c|c|c|}
\hline $\begin{array}{l}\text { Solutions and RTD } \\
\text { challenges }\end{array}$ & Short term (2014) & Mid term (2018) & Longer term (2022) \\
\hline $\begin{array}{l}\text { Content } \\
\text { management tools }\end{array}$ & $\begin{array}{l}\text { Media Internet } \\
\text { technologies }\end{array}$ & $\begin{array}{l}\text { Scalable multimedia } \\
\text { compression and } \\
\text { transmission }\end{array}$ & Immersive multimedia \\
\hline Collaboration tools & $\begin{array}{l}\text { Crowd-based location } \\
\text { content; augmented } \\
\text { reality tools }\end{array}$ & $\begin{array}{l}\text { Content and context } \\
\text { fusion technologies }\end{array}$ & $\begin{array}{l}\text { Intelligent content } \\
\text { objects; large scale } \\
\text { ontologies and } \\
\text { semantic content }\end{array}$ \\
\hline $\begin{array}{l}\text { Cloud services and } \\
\text { software } \\
\text { components }\end{array}$ & City-based clouds & $\begin{array}{l}\text { Open and federated } \\
\text { content platforms }\end{array}$ & $\begin{array}{l}\text { Cloud-based fully } \\
\text { connected city }\end{array}$ \\
\hline $\begin{array}{l}\text { Smart systems based } \\
\text { on Internet of Things }\end{array}$ & $\begin{array}{l}\text { Smart power } \\
\text { management } \\
\text { Portable systems }\end{array}$ & $\begin{array}{l}\text { Smart systems } \\
\text { enabling integrated } \\
\text { solutions e.g. health } \\
\text { and care }\end{array}$ & $\begin{array}{l}\text { Software agents and } \\
\text { advanced sensor } \\
\text { fusion; telepresence }\end{array}$ \\
\hline
\end{tabular}

Demand for e-services in the domains outlined in Fig. 1 is increasing, but not at a disruptive pace. There is a critical gap between software applications and the provision of e-services in terms of sustainability and financial viability. Not all applications are turned into e-services. Those that succeed in bridging the gap rely on successful business models that turn technological capabilities into innovations, secure a continuous flow of data and information, and offer useful services. It is here that the third task for city authorities comes into play, that of creating business models that sustain the long-term operation of smart cities. To date, the environment for applications and their business models has been very complex, with limited solutions available 'off the shelf', a lot of experimentation, and many failures. Cities currently face a problem of standardisation of the main building blocks of smart / intelligent cities in terms of applications, business models, and services. Standardisation would dramatically reduce the development and maintenance costs of e-services due to cooperation, exchange 
and sharing of resources among localities. Open source communities may also substantially contribute to the exchange of good practices and open solutions.

The current research on smart cities is partly guided by the above priorities of contemporary urban development and city governance. Large companies in the ICT sector, such as IBM, Cisco, Microsoft, are strongly involved in and are contributing to shaping the research agenda. EU research within the context of the FP7 and CIP programmes also aims at stimulating a wider uptake of innovative ICT-based services for smart cities, linking smart cities with user-driven innovation, future Internet technologies, and experimental facilities for exploring new applications and innovative services.

Technology push is still dominant in the actual research agenda. A recent Forrester survey states that smart city solutions are currently more vendor push than city government pull based. However, the survey points out that, "smart city solutions must start with the city not the smart" [14]. The positive impact of available smart city solutions on European cities has not yet been demonstrated, nor have the necessary funding mechanisms and business models for their sustainability been developed. Creating the market constitutes the first priority. Innovation ecosystems for smart cities have to be defined, in terms of applications, services, financial engineering and partnerships. This will help cities to secure funding, identify revenue streams, broker public-private partnerships, and open public data up to developers as well as user communities. As the major challenge facing European cities is to secure high living standards through the innovation economy, smart cities must instrument new ways to enhance local innovation ecosystems and the knowledge economy overall.

\section{Future Internet Experimentation and Living Labs Interfaces}

In exploring the role of Future Internet experimentation facilities in benefiting urban development as we move towards smart cities, we will succinctly summarise the role of experimental facilities and the experimentation process, as well as the potential role of the 'Living Labs' concept in enriching experimentally-driven research on the Future Internet. Within the context of the now emerging FIRE portfolio [15], the potential exists to support new classes of users and experiments combining heterogeneous technologies that represent key aspects of the Future Internet. The considerable obstacles of complexity and unfamiliarity that are faced when trying to explore the effects of new applications that bring future users the increasing power of the Future Internet have not yet been overcome. Issues that are being dealt with in the attempt of FIRE projects to move closer to the goal of a federated testbed facility, and which are also important in collaborating with smart city and Living Labs activities, are authentication and access to facilities; security and privacy as well as IPR protection; operation and research monitoring as well as experiment control; and the issue of defining and monitoring experiments in large-scale usage settings.

The portfolio of FIRE experimentation projects shows that users in such FIRE projects are mostly academic and industry researchers. End-user involvement and end user experimentation is beyond the current scope of FIRE, although some interesting initiatives in that respect have started such as the Smart Santander project (services and applications for Internet of Things in the city), the TEFIS project (platform for 
managing experimental facilities, among which Living Labs) and the ELLIOT project (co-creation of wellbeing, logistics and environment IoT-based services).

A comparison of the role of users in FIRE facilities projects compared to Living Labs is presented in Table 3. Importantly, FIRE projects typically involve users in assessing the impacts of technologies in socio-economic terms, whereas Living Labs projects aim to engage users in the innovation process itself. Also, the predominant approach of FIRE facilities is controlled experimentation, whereas Living Labs engage users in the actual innovation process (co-creation). The European Commission has voiced its support for stronger user orientation in the Future Internet facilities projects; not only users in terms of academic and industry researchers who will use these facilities for their research projects, but also end-users. Emphasis is on involving communities of end-users at an early stage of development to assess the impacts of technological changes, and possibly engage them in co-creative activities.

Table 3. User Role in FIRE and Living Labs

\begin{tabular}{|c|c|c|}
\hline & Future Internet Experiments & Living Labs Innovation \\
\hline Approach & $\begin{array}{l}\text { Controlled experiments } \\
\text { Observing large-scale deployment } \\
\text { and usage patterns } \\
\text { Federated testbeds }\end{array}$ & $\begin{array}{l}\text { Both controlled and natural } \\
\text { situation experiments } \\
\text { User co-creation via Living Labs } \\
\text { methodologies, action research } \\
\text { Open, cooperative innovation }\end{array}$ \\
\hline Object of testing & $\begin{array}{l}\text { Technologies, services, architec- } \\
\text { tures, platforms, system require- } \\
\text { ments; impacts }\end{array}$ & $\begin{array}{l}\text { Validation of user ideas, prototype } \\
\text { applications and solutions. Testing } \\
\text { as joint validation activity }\end{array}$ \\
\hline Scale of testing & Large-scale mainly & From small to large scale \\
\hline Stakeholders & $\begin{array}{l}\text { FI Researchers (ICT industry \& } \\
\text { academia) }\end{array}$ & $\begin{array}{l}\text { IT multidisciplinary researchers, } \\
\text { End-users, } \\
\text { enterprises (large \& SMEs) }\end{array}$ \\
\hline Objective & $\begin{array}{l}\text { Facilities to support research } \\
\text { Impact assessment of tested solutions }\end{array}$ & $\begin{array}{l}\text { Support the process of user-driven } \\
\text { innovation as co-creation }\end{array}$ \\
\hline
\end{tabular}

In order to explore the opportunities and interfaces, we will now take a further look at Living Labs. The Web 2.0 era has pushed cities to consider the Internet, including mobile networks, as a participative tool for engaging citizens and tourists. Many initiatives have been launched by cities, such as Wikicity in Rome stemming from MIT's Senseable City Lab which studies the impact of new technologies on cities, RealTime City Copenhagen, and Visible City Amsterdam. This collection of initiatives already looks like a "networked Living Lab" of cities for investigating and anticipating how digital technologies affect people as well as how citizens are "shaping" those technologies to change the way people are living and working.

Apart from the diversity of research streams and related topics for designing alternatives of the Internet of tomorrow, it becomes increasingly challenging to design open infrastructures that efficiently support emerging events and citizens' changing needs. Such infrastructure also creates many opportunities for innovative services such as green services, mobility services, wellbeing services, and playable city ser- 
vices based on real-time digital data representing digital traces of human activity and their context in the urban space. Environmental sensors measure parameters such as air quality, temperature or noise levels; telecommunication networks reflect connectivity and the location of their users; transportation networks digitally manage the mobility of people and vehicles as well as products in the city, just to give a few examples. Today, it is becoming increasingly relevant to explore ways in which such data streams can become tools for people taking decisions within the city. Promising applications and services seem to be emerging from user co-creation processes.

Recent paradigms, such as open innovation and open business models [16], Web 2.0 [17] as well as Living Labs [18], a concept originating from the work of William Mitchell at MIT and currently considered as user-driven open innovation ecosystems, promote a more proactive and co-creative role of users in the research and innovation process. Within the territorial context of cities, rural areas and regions, the main goal of Living Labs is to involve communities of users at an early stage of the innovation process. The confrontation of technology push and application pull in a Living Lab enables the emergence of breakthrough ideas, concepts and scenarios leading to adoptable innovative solutions. Some of the methodologies used in Living Labs innovation projects demonstrate a potential interface with FIRE experimentation approaches. In [19], a useful classification is elaborated of different platforms for testing and experimentation including testbeds, prototyping projects, field trials, societal pilots and Living Labs. In [20] a landscape of user engagement approaches is presented. Methodologies for Living Labs organisation, phased development and process management integrated with user experiments within an action research setting have been developed and implemented in [21].

Altogether, Future Internet experimental facilities, Living Labs and Urban development programmes form an innovation ecosystem consisting of users and citizens, ICT companies, research scientists and policy-makers. In contrast with a testbed, a Living Lab constitutes a "4P" (Public, Private and People Partnership) ecosystem that provides opportunities to users/citizens to co-create innovative scenarios based on technology platforms such as Future Internet technology environments involving large enterprises and SMEs as well as academia from different disciplines. It appears that Future Internet testbeds could be enabling the co-creation of innovative scenarios by users/citizens contributing with their own content or building new applications that would mash-up with the city's open, public data.

\section{Emerging Smart City Innovation Ecosystems}

As Table 4 illustrates, several FP7-ICT projects are devoted to research and experimentation on the Future Internet and the Internet of Things within cities, such as Smart Santander and, within the IoT cluster, ELLIOT. The CIP ICT-PSP programme has initiated several pilot projects dedicated to smart cities and Living Labs, some with a clear Future Internet dimension (Apollon, Periphèria, and to a less extent too, Open Cities and EPIC). Among the earlier projects with interesting aspects on the interface of Living Labs and Future Internet is C@R (FP6). 
The Smart Santander project proposes an experimental research facility based on sensor networks which will eventually include more than 20,000 sensors, considered as IoT devices. The architecture supports a secure and open platform of heterogeneous technologies. The project is intended to use user-driven innovation methods for designing and implementing 'use cases'. Bus tracking and air quality (EKOBUS: a map of sensor data available on smart phone) as well as urban waste management are two of the use cases from the Smart Santander project.

Table 4. Examples of Living Lab Initiatives Related to Smart Cities, Rural Areas and Regions

\begin{tabular}{|c|c|}
\hline $\begin{array}{l}\text { Cities and } \\
\text { urban areas }\end{array}$ & $\begin{array}{l}\text { - Smart Santander (FP7-ICT, 2010). Internet services and sensor network } \\
\text { in the city. www.smartsantander.eu } \\
\text { ELLIOT (FP7-ICT, 2010). Experimental Living Lab for Internet of } \\
\text { Things. Three Living Labs are involved. http://www.elliot-project.eu/ } \\
\text { - } \quad \text { Periphèria (CIP ICT-PSP, 2010). Internet of Things in Smart City. } \\
\text { www.peripheria.eu } \\
\text { - } \quad \text { Open Cities (CIP ICT-PSP, 2010). Public sector services. } \\
\text { - } \quad \text { EPIC (CIP ICT-PSP, 2010). Platforms for intelligent cities. } \\
\text { Apollon (CIP ICT-PSP, 2010). Domain-specific Pilots of Living Labs in } \\
\text { cross-border networks, targeting city areas. www.apollon-pilot.eu }\end{array}$ \\
\hline $\begin{array}{l}\text { Villages in } \\
\text { rural areas } \\
\text { and regions }\end{array}$ & $\begin{array}{l}\text { - } \quad \text { Collaboration@Rural-C@ } @ \text { R (FP6-ICT, 2006-2010). Six Living Labs in } \\
\text { Rural areas using a common service platform. www.c-rural.eu } \\
\text { - } \quad \text { Networking for Communications Challenges Communities (N4C). Ex- } \\
\text { tending Internet access to remote regions. www.n4c.eu } \\
\text { - } \quad \text { MedLab (Interreg IVc). Living Labs and Regional Development. }\end{array}$ \\
\hline
\end{tabular}

The ELLIOT project (Experiential Living Lab for the Internet of Things) represents a clear example of Living Labs and Future Internet interaction, elaborating three IoT use cases in three different Living Labs. The first use case is dedicated to co-creation by users of green services in the areas of air quality and ambient noise pollution with innovative devices such as the "green watch" (http://www.lamontreverte.org/en/) and customised sensors being used by citizens. The second one addresses wellbeing services in connection with a hospital and the third focuses on logistic services in product development facilities with professional users. Its goal is to investigate evidence of the social dynamics of the Living Lab approach for the purpose of ensuring a wide and rapid spread of innovative solutions through socio-emotional intelligence mechanisms.

The green services use case takes place in the context of the ICT Usage Lab and within the Urban Community of Nice - Cote d'Azur (NCA). This use case involves local stakeholders, such as the regional institution for air measurement quality (Atmo PACA), the local research institute providing the IoT-based green service portal and managing the experiments (INRIA/AxIS), the Internet Foundation for the New Generation (FING) facilitating user workshops, and a local SME providing data access from electric cars equipped with air quality sensors (VULog) and a citizen IT platform (a regional Internet space for citizens in the NCA area). The objectives of the IoT-based green services use case are twofold: to investigate experiential learning of the IoT in an open and environmental data context, and to facilitate the co-creation of 
green services based on environmental data obtained via sensors. Various environmental sensors will be used, such as fixed sensors from Atmo PACA in the NCA area, fixed Arduino-assembled sensors by citizens, mobile sensors, such as citizen-wired green watches or sensors installed on electric vehicles. The backbone of the green services use case is an IoT-based service portal which addresses three main IoTrelated portal services by allowing the user: 1) to participate in the collection of environmental data; 2) to participate in the co-creation of services based on environmental data; and 3) to access services based on environmental data, such as accessing and/or visualising environmental data in real time. Three complementary approaches have already been identified as relevant for the green services use case: participatory/usercentred design methods; diary studies for IoT experience analysis, and coupling quantitative and qualitative approaches for portal usage analysis. In this context of an open innovation and Living Lab innovation eco-system, focus groups involving stakeholders and/or citizen may be run either online or face-to-face.

The Periphèria project is among the Smart Cities portfolio of seven projects recently launched in the European Commission ICT Policy Support Programme. Their aim is to develop smart cities infrastructures and services in real-life urban environments in Europe. Actually, the Periphèria project forms a bridge between the Smart Cities portfolio of projects and the Internet of Things European Research Cluster (IERC) and can therefore be taken as a model of Smart Cities and Future Internet integration. At the core of Periphèria lies the role of Living Labs in constituting a bridge between Future Internet technology push and Smart City application pull, re-focusing the attention on "People in Places" to situate the human-centric approach within physical urban settings. People in Places becomes the context and the situation - including the relational situations between people and between people and spaces, infrastructures, services, etc. - in which the integration of Future Internet infrastructures and services occurs as part of a "discovery-driven" process. The Cloud is considered to be a resource environment that is dynamically configured (run-time) to bring together testbeds, applets, services, and whatever is relevant, available and configured for integration at the moment that the social interaction of People in Places calls for those services.

Participation is at the heart of this bottom-up approach to Future Internet technology integration, whereby Future Internet research adopts a "competitive offer" stance to prove its added value to users. Platform and service convergence is promoted by the use of serious games that engage citizens and users in the process of discovering the potential of Future Internet technologies and the possible sustainable scenarios that can be built upon them. Serious gaming thus constitutes a mechanism to enhance participation and transform individual and collective behaviour by working directly on the social norms that shape them; in addition, they constitute a monitoring and governance platform for increasing self-awareness of the changes brought about by the adoption of Future Internet technologies. Periphèria has identified five archetypal urban settings: (1) the Smart Neighbourhood where media-based social interaction occurs; (2) the Smart Street where new mobility behaviours develop; (3) the Smart Square where participatory civic decisions are taken; (4) the Smart Museum and Park where natural and cultural heritage feed learning; and (5) the Smart City Hall where mobile e-government services are delivered.

As an example (see Fig. 2), the City of Genova is experimenting with the Smart Museum and Park arena, with to the aim of blending the fruition of the city's natural 
and cultural heritage with safety and security in urban spaces. This approach draws on and integrates Future Internet technologies (such as augmented reality services for the appreciation of cultural heritage) with networks of video-cameras used to monitor public spaces. In addition, the integration of these services occurs in the Living Lab context where citizens contribute both to the definition and prioritisation of the cultural heritage in their city and also to an exploration of the privacy and security issues that are central to the acceptance and success of Future Internet services for the safety of urban environments.

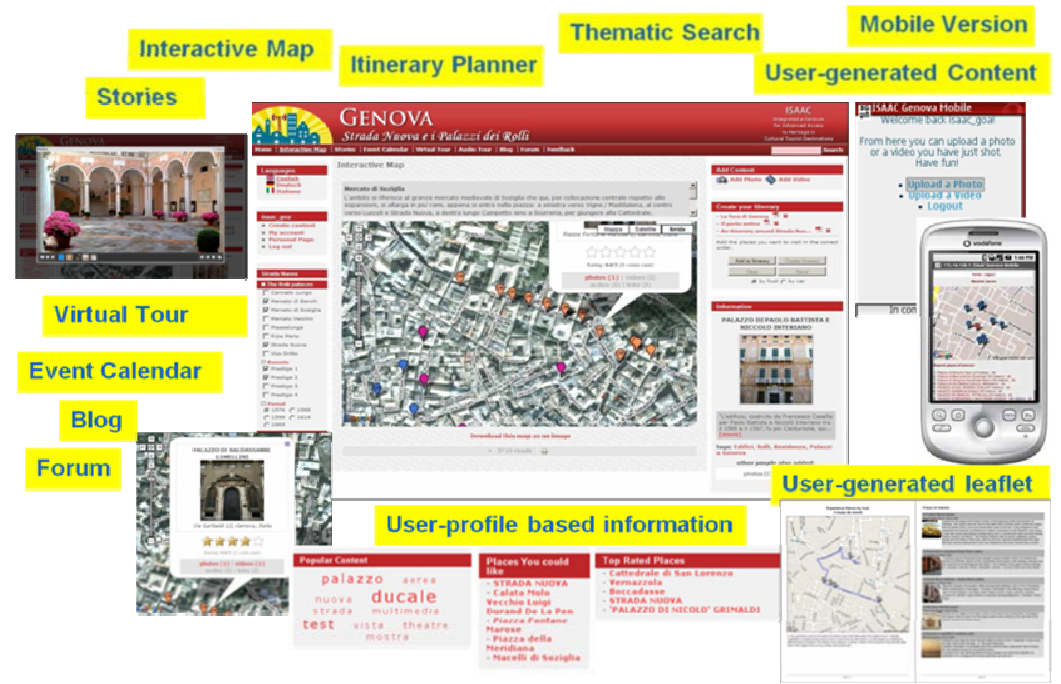

Fig. 2. Genoa smart city experiments on Smart Museum and Smart Park

This example illustrates the central role of users and citizens in defining the services that make up a Smart City as well as the new sustainable lifestyles and workstyles made possible by Future Internet technologies. In addition, it shows how the Future Internet is a mixture of technologies and paradigms with overlapping implementation time-frames. While the deployment of IPv6 networks may be a medium-term effort, other Future Internet paradigms such as cloud services and camera and sensor networks can be considered as already operational. The discovery-driven arena settings in Periphèria are guiding the development of Living Lab-convergent service platforms that bring these technologies together into integrated, dynamic co-creation environments that make up a Smart City.

These projects examples provide initial examples of collaboration models in smart city innovation ecosystems, governing the sharing and common use of resources such as testing facilities, user groups and experimentation methodologies. Two different layers of collaboration can be distinguished. The first layer is collaboration within the innovation process, which is understood as ongoing interaction between research, technology and applications development and validation and utilisation in practice. Cases mentioned above such as ELLIOT, SmartSantander and Periphèria constitute typical arenas where potential orchestrations of these interactions are explored. Still, many 
issues need to be clarified such as how the different research and innovation resources in a network, such as specific testing facilities, tools, data and user groups, can be made accessible and adaptable to specific demands of any research and innovation projects.

The second layer concerns collaboration at the territorial level, driven by urban and regional development policies aiming at strengthening the urban innovation systems through creating effective conditions for sustainable innovation. This layer builds on Michael Porter's concept of "national competitive advantage" [22] which borrows the 'national systems of innovation' thinking, which was originally developed by Chris Freeman. Following this thinking, the "urban value creation system" can be considered as being shaped by four determinants: 1) physical and immaterial infrastructure, 2) networks and collaboration, 3) entrepreneurial climate and business networks, 4) demand for services and availability of advanced end-users (see Fig. 3). Additionally, the value creation system in its conceptualisation by Michael Porter is affected by policy interventions aimed at stimulating the building of networks, the creation of public-private partnerships, and the enhancement of innovative conditions.

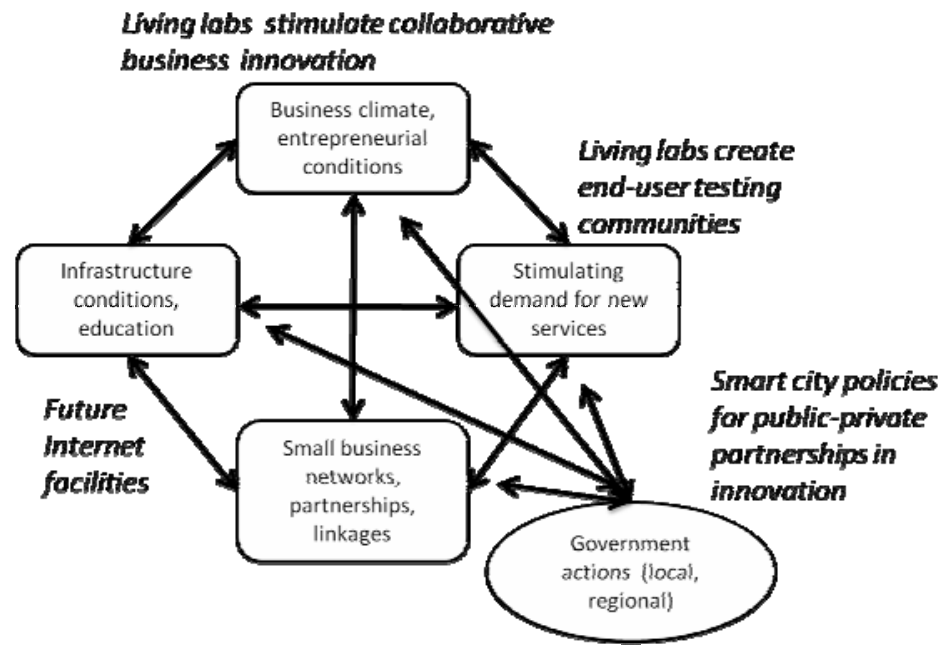

Fig. 3. Conceptualisation of smart city value creation and innovation system (based on Porter)

The challenge in this layer is to create a collaborative approach to innovation ecosystems based on sustainable partnerships among the main stakeholders from business, research, policy and citizen groups and achieve an alignment of local, regional and European policy levels and resources. The ELLIOT project is an example of a Future Internet research and innovation project embedded in regional and even national innovation policy. From the perspective of smart cities, managing innovation at the level of urban innovation ecosystems becomes a task of managing the portfolio of resources and fostering fruitful interlinkages. Smart city innovation ecosystem management aims to manage the portfolio of "innovation assets" made up of the different facilities and resources, by creating partnerships among actors that govern these assets, by fostering knowledge and information flows, and by providing open access to resources made available to users and developers. 


\section{Conclusions and Outlook}

In this paper we explored the concept of "smart cities" as environments of open and user driven innovation for experimenting and validating Future Internet-enabled services. Smart cities are enabled by advanced ICT infrastructure contributed to by current Future Internet research and experimentation. Such infrastructure is one of the key determinants of the welfare of cities. Other determinants of the welfare of cities will be important as well: the infrastructure for education and innovation, the networks between businesses and governments, the existence of demanding citizens and businesses to push for innovation and the quality of services. Here we see a clear analogy to Porter's concept of national competitive advantage: the welfare potential of cities and urban areas.

The Living Labs concept represents a powerful view of how user-driven open innovation ecosystems could be organised. As a concept applied to smart cities it embodies open business models of collaboration between citizens, enterprises and local governments, and the willingness of all parties -including citizens and SMEs- to engage actively in innovation. The Living Lab concept should be considered also as a methodology, a model for organising specific innovation programmes and innovation projects and conducting innovation experiments. Whereas the last aspect has gained most attention, both levels and their interaction are important: shaping and operating the innovation ecosystem.

Based on an analysis of challenges of smart cities on the one hand and current projects in the domain of Future Internet research and Living Labs on the other, common resources for research and innovation can be identified, such as testbeds, Living Lab facilities, user communities, technologies and know-how, data, and innovation methods. Such common resources potentially can be shared in open innovation environments. Two layers of collaboration were distinguished that govern the sharing of these resources. One layer focuses on the actual resources within the Future Internet research and innovation process, the second layer addresses the urban innovation system. Several projects discussed in this paper provide evidence of collaboration models for sharing resources at both layers, e.g. the use of Living Lab facilities and methods in experimenting on Future Internet technologies, and the use of Living Lab methodologies for implementing innovation policies of cities.

The potential types and structures of these collaboration frameworks and the concrete issues to be resolved in sharing of research and innovation resources, such as governance, ownership, access, transferability and interoperability need further examination and also need development and piloting in future pilot projects. The current experimentation and innovation approaches used in some of the FIRE and Living Lab projects should be studied more closely in order to develop concrete examples of resource sharing opportunities. Initial examples of resource sharing appear in making user communities available for joint use with Future Internet facilities (e.g. the TEFIS project), and in making accessible Future Internet facilities for developing and validating IoT-based service concepts and applications through Living Labs approaches for smart cities (e.g. the SmartSantander and ELLIOT projects).

The Future Internet constitutes both a key technology domain and a complex societal phenomenon. Effective, user driven processes of innovation, shaping and application of 
Future Internet technologies in business and society are crucial for achieving socioeconomic benefits. A key requirement emphasised in this paper is how, within an environment of open innovation in smart cities and governed by cooperation frameworks, the diverse set of resources or assets that constitutes the "engine" of ongoing research and innovation cycles can be made open accessible for users and developers.

Open Access. This article is distributed under the terms of the Creative Commons Attribution Noncommercial License which permits any noncommercial use, distribution, and reproduction in any medium, provided the original author(s) and source are credited.

\section{References}

1. Kroes, N.: European Commissioner for Digital agenda, The critical role of cities in making the Digital Agenda a reality. Closing speech to Global Cities Dialogue Spring Summit of Mayors Brussels, 28 May (2010)

2. Caragliu, A., Del Bo, C., Nijkamp, P.: Smart cities in Europe. Series Research Memoranda 0048. VU University Amsterdam, Faculty of Economics, Business Administration and Econometrics (2009)

3. Eurocities: Strategic Policy Paper on Broadband in Cities (2010)

4. Eurocities: Cities and Innovation in Europe. Discussion paper (2010)

5. Von Hippel, E.: Democratizing Innovation. The MIT Press, Cambridge (2005)

6. Gibson, D.V., Kozmetsky, G., Smilor, R.W. (eds.): The Technopolis Phenomenon: Smart Cities, Fast Systems, Global Networks. Rowman \& Littlefield, New York (1992)

7. WFSC: Smart Communities, http: / /www. smartcommunities.org/about.htm

8. Komninos, N.: Intelligent Cities: Innovation, knowledge systems and digital spaces. Taylor \& Francis, London and New York (2002)

9. Komninos, N.: Intelligent Cities and Globalisation of Innovation Networks. Routledge, London and New York (2008)

10. Chen-Ritzo, C.H., Harrison, C., Paraszczak, J., Parr, F.: Instrumenting the Planet. IBM Journal of Research \& Development 53(3), 338-353 (2009)

11. European Commission: Growing Regions, Growing Europe: Fifth progress report on economic and social cohesion. European Commission COM(2008) 371 final (2008)

12. European Commission: Future Media Internet: Research challenges and road ahead. DG Information Society and Media, Luxembourg, Publications Office of the European Union (2010)

13. European Commission: Future Media Networks: Research challenges 2010. DG Information Society and Media, Luxembourg, Publications Office of the European Union (2010)

14. Belissent, J.: Getting clever about smart cities: New opportunities require new business models. Forrester for Ventor Strategy Professionals (2010)

15. European Commission, DG INFSO: Future Internet Research and Experimentation (September 2010)

16. Chesbrough, H.W.: Open Innovation: The New Imperative for Creating and Profiting from Technology. Harvard Business School Press, Boston (2003)

17. O'Reilly, T., Battelle, J.: Web Squared: Web 2.0 Five Years On. Special Report, Web 2.0 Summit, Co-produced by O'Reilly \& Techweb (2009)

18. European Commission, DG INFSO: Advancing and Applying Living Lab Methodologies (2010)

19. Ballon, P., Pierson, J., Delaere, S., et al.: Test and Experimentation Platforms for Broadband Innovation. IBBT/VUB-SMIT Report (2005) 
20. Pallot, M., Trousse, B., Senach, B., Scapin, D.: Living Lab Research Landscape: From User Centred Design and User Experience Towards User Co-creation. Position Paper, First Living Labs Summer School (http: / /www-sop. inria.fr/11ss2010/), Paris (August. 2010)

21. Schaffers, H., Garcia Guzmán, J., Navarro, M., Merz, C. (eds.): Living Labs for Rural Development. TRAGSA, Madrid (2010), http: / / www. c-rural .eu

22. Porter, M.: The Competitive Advantage of Nations. Free Press, New York (1990) 